\title{
Dielectrophoretic Selection of Viable Single-cells of Rice and Tobacco
}

\author{
Mikako SAITO, * Shigetoshi HORIKIRI, and Hideaki MATSUOKA
}

\author{
Department of Biotechnology and Life Science, Tokyo University of Agriculture and Technology (Koganei, Tokyo \\ 184-8588, Japan)
}

Received November 22, 2002 ; Accepted February 7, 2003

\begin{abstract}
A carbon fiber microelectrode (CFM) was devised and applied to the dielectrophoretic selection of a viable single-cell of rice and BY-2. When $10 \mathrm{MHz}$ electric field was applied, only a viable single-cell could be pulled and picked up within a few sec. This cell selection system was thought to be useful for the high throughput experiment using single-cells.
\end{abstract}

Key Words : Single-cell Experiment, Carbon Fiber Microelectrode, Cell Viability, Protoplast

\section{Introduction}

In the post-genome era, a great deal of genome information is available and accordingly it is frequently required to study not only the function of a particular single gene but also the associative functions of multiple genes in the same cell in vivo. From this viewpoint, the single-cell gene experiment has now been recognized as an important method. The single-cell gene experiment implies the selection of a proper single-cell, ${ }^{1,2}$ the transportation of the cell to a proper site, the microinjection of genes into the cell, ${ }^{3)}$ the application of a stimulating signal to the cell, ${ }^{4,5}$ and the measurement of the gene expression of the cell. ${ }^{6)}$ In order to increase the success efficiency as a whole, it is important to check the cell viability and to remove dead or wounded cells at as early step as possible. For this purpose, we have devised a carbon fiber microelectrode (CFM) and applied it to the dielectrophoretic selection of a viable single-cell. The fabrication of the CFM is much easier than more elegant microelectrodes reported formerly. ${ }^{1,2)}$

The principle of the dielectrophoresis of viable cells (microbial, plant, and animal cells) was well described elsewhere. $^{7-9)}$ The dielectrophoretic force working between a cell and an electrode (F) depends upon such parameters as the cell diameter ( $r)$, the intensity of a nonuniform electric field $(|\mathrm{E}|)$, the dielectric constants (absolute values of the complex permittivity) of a cell $\left(\varepsilon_{\text {cell }}\right)$ and its suspending solution $\left(\varepsilon_{\text {Soln }}\right)$ :

$$
\mathrm{F}=2 \pi \mathrm{r}^{3} \varepsilon_{\text {Soln }}\left(\frac{\varepsilon_{\text {cell }}-\varepsilon_{\text {Soln }}}{\varepsilon_{\text {Cell }}+2 \varepsilon_{\text {Soln }}}\right) \vec{\nabla}|\mathrm{E}|^{2}
$$

In general, the magnitudes of $\varepsilon_{\text {cell }}$ and $\varepsilon_{\text {Soln }}$ decrease as the frequency increases. However they are not entirely coincident over the frequency range of the applied electric field. At a frequency where $\mathcal{E}_{\text {cell }}$ is greater than $\varepsilon_{\text {Soln }}$, the cell is pulled towards strongest field region (i.e. near the carbon fiber microelectrode). We call this the positive force. Where $\varepsilon_{\text {cell }}$ is smaller than $\varepsilon_{\text {soln }}$, the cell moves towards weakest field region (i.e. near the counter $\mathrm{Pt}$ plate electrode). We call this the negative force. This study concerns only whether the dielectric force is positive or negative in this sense, and therefore, is aimed at finding such a frequency range where viable and dead cells would move towards opposite directions.

\section{1 Plant cells}

\section{Experimental}

Plant cells used in this study are protoplasts of rice (Oryza sativa L. japonica cv. Nipponbare) and tobacco (Nicotiana tabacum L. cv. line BY-2). The rice protoplasts were prepared as follows. Rice cells were cultured for 4 days with rotation in $\mathrm{LQ}$ medium ${ }^{10)}$ at $25^{\circ} \mathrm{C}$. Then the cells (calli) were separated by the centrifugation and rinsed with a washing solution (mannitol $0.5 \mathrm{M}, \mathrm{CaCl}_{2}$ $0.1 \mathrm{mM}$ ). Then the cells were suspended in an enzyme solution (Pectolyase Y-23 (Kikkoman Co. Ltd., Tokyo) $0.05 \% \mathrm{w} / \mathrm{v}$, Cellulase Onozuka RS (Yakult Honsha Co. Ltd., Tokyo) $2 \%, \mathrm{CaCl}_{2}-2 \mathrm{H}_{2} \mathrm{O} 0.01 \%$, K-dextran sulfate $0.1 \%$, mannitol $9 \%, \mathrm{pH} 5.6$ ) and incubated on a shaker (30 rpm) for $1 \mathrm{hr}$ at $30^{\circ} \mathrm{C}$ in the dark and then stood still for a successive $2 \mathrm{hr}$ without shaking at $30^{\circ} \mathrm{C}$. This suspension was passed through a nylon mesh (mesh size 20 $\left.\mu \mathrm{m}^{\circ}\right)$ to remove callus debris. Then the protoplasts were collected by the centrifugation, washed and finally suspended in a protoplast medium (PP medium) ${ }^{11)}$.

BY-2 cells were cultured in LSD medium ${ }^{12)}$ at $28^{\circ} \mathrm{C}$ for 4 days with rotation. The cells were collected by the centrifugation. Subsequent procedure for the preparation of the protoplast was same as above. \section{2 Fabrication of a carbon fiber microelectrode} (CFM)

A carbon fiber with a diameter of $10 \mu \mathrm{m}$ was inserted in a glass capillary with a diameter of $1 \mathrm{~mm}$. The glass capillary was heated and pulled to form a small tip with a diameter of about $30-50 \mu \mathrm{m}$. The tip was finished with a micro forge to seal the possible gap between the carbon fiber and the glass capillary. Carbon powder was put into the capillary from the big end. A lead was inserted from the big end of the capillary to make an electric contact 


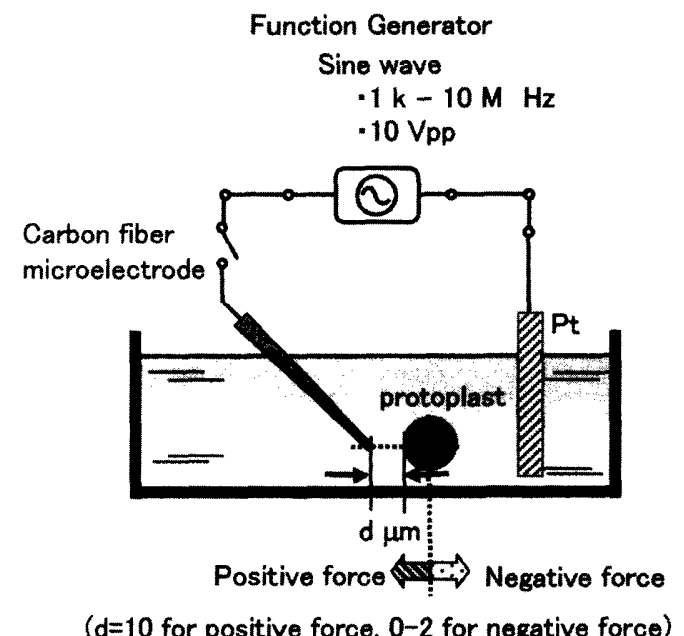

Fig. 1 Experimental setup for the dielectrophoretic selection of a viable single-cell.

with the carbon powder and then the big end of the capillary was sealed with wax.

\section{3 Measurement of dielectrophoretic behavior}

A test cell was set at the center of the microscope view and the tip of a CFM was situated $10 \mu \mathrm{m}$ apart from the cell (Fig. 1). Alternating sinusoidal electric field was applied between the CFM and a Pt counter electrode. The voltage was $10 \mathrm{~V}_{\mathrm{PP}}$ (peak to peak) and the frequency was varied from $1 \mathrm{kHz}$ to $10 \mathrm{MHz}$. When the test cell pulled towards the CFM within a few seconds, the dielectrophoretic force was determined as positive. When the cell did not move, the CFM was brought close to the cell and successively observed if the cell moved away from the CFM. When the cell moved away from the CFM, the dielectrophoretic force was determined as negative. About 20-30 cells were investigated per each frequency and the relative value $100 \times\left(\mathrm{N}_{+-} \mathrm{N}_{-}\right) / \mathrm{N}_{\mathrm{T}}(\%)$ was plotted versus the frequency, where $\mathrm{N}_{+}, \mathrm{N}_{-}$were the numbers of cells that showed positive force and negative force, respectively. $\mathrm{N}_{\mathrm{T}}$ was the total number of cells that were assayed.

\section{4 Staining of cells with propidium iodide (PI)}

As a comparison, the viability of cells was checked also by a conventional staining method using PI. When cells are treated with saponin, the cell membrane structure is collapsed and consequently the cell will become dead. PI is known to be able to permeate thus collapsed membrane and react with DNA to form a red fluorescent conjugate. Therefore the saponin treated cells and PIstainable cells may be regarded as dead cells equivalently. Thus we investigated correlation between PIstainability and dielectrophoretic property of saponin treated cells. Protoplasts were suspended in a PI solution and observed under a fluorescent microscope. Nonfluorescent cells were regarded as viable cells.

\section{Results and Discussion}

3. 1 Dynamic movement of single-cells in response to the electric field application

When $15 \mathrm{MHz}$ electric field was applied to a rice cell, the cell began to move within $1 \mathrm{sec}$ and reached the CFM around 6 sec (Fig. 2(A)). On the other hand, when
(A)

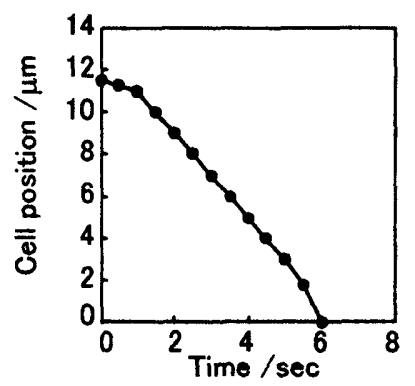

(B)

(C)

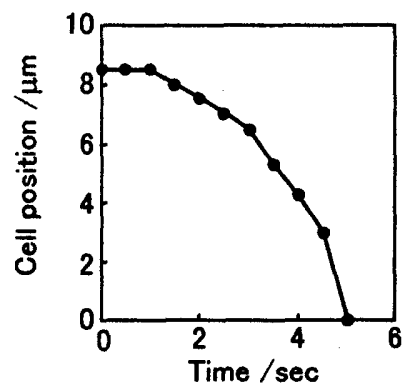

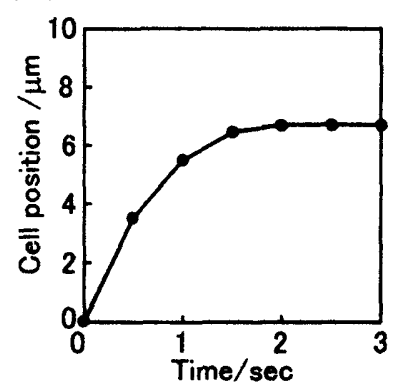

(D)

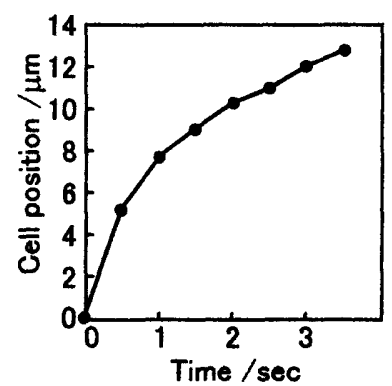

Fig. 2 Dynamic movement of single-cell in response to the electric field application. (A) Single-cell of rice at $15 \mathrm{MHz}$, positive force. (B) Single-cell of rice at $100 \mathrm{kHz}$, negative force. (C) Single-cell of BY-2 at $10 \mathrm{MHz}$, positive force. (D) Single-cell of BY-2 at $100 \mathrm{kHz}$, negative force.

$100 \mathrm{kHz}$ electric field was applied to a rice cell, the cell did not move for $30 \mathrm{sec}$. Then the CFM was brought close to the cell and $100 \mathrm{kHz}$ electric field was applied to the cell again. Then the cell was repelled immediately (Fig. 2(B)). Similar phenomena were observed with a BY-2 cell (Fig. 2(C),(D)).

\section{2 Frequency dependence of dielectrophoresis}

Test cells were treated with $0.3 \%$ saponin to obtain the sample of dead cells. The cells used without saponin treatment were regarded as viable control cells. As shown in Fig. 3(A), more than $80 \%$ of viable rice cells (27 out of 33 cells) showed negative dielectrophoretic force in the range from $100 \mathrm{kHz}$ to $2 \mathrm{MHz}$ while positive force above $9 \mathrm{MHz}$. In contrast, most of dead rice cells (18 out of 20 cells) showed no movement at $100 \mathrm{kHz}$ and about $50 \%$ of dead cells (10 out of 20 cells) showed negative force in the range from $100 \mathrm{kHz}$ to $10 \mathrm{MHz}$. Therefore, if the frequency was adjusted above $6 \mathrm{MHz}$, only viable cells of rice were pulled towards the CFM and could be picked up with the CFM.

BY-2 cells showed a similar property to rice cells. As shown in Fig. 3(B), more than $80 \%$ of viable BY-2 cells showed negative force in the range from $100 \mathrm{kHz}$ to 1 $\mathrm{MHz}$ while positive force above $6 \mathrm{MHz}$. The dead cells showed no positive force throughout. Therefore, if the frequency was adjusted above $6 \mathrm{MHz}$, only viable cells of BY-2 could be picked up.

3. 3 Comparison between the dielectrophoretic property and PI staining property

The protoplasts that could be stained and not be stained with PI were selected, respectively, and each cell was investigated for its dielectrophoretic movement at 15 
(A)

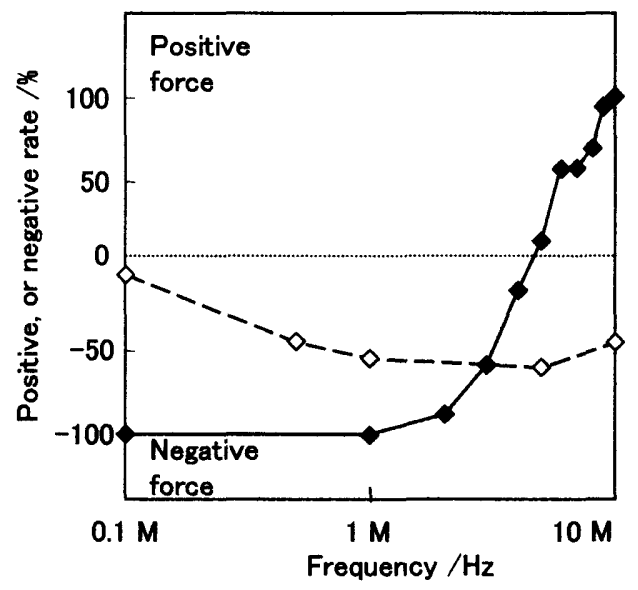

(B)

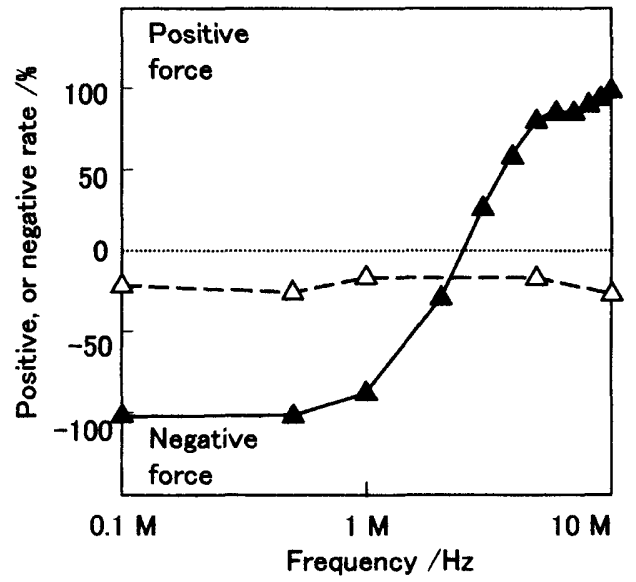

Fig. 3 Frequency dependence of dielectrophoretic movement. (A) Rice single-cells, $(\diamond)$ viable cells $(n=33),(\diamond)$ dead cells $(n=20)$. (B) BY-2 single-cells, $(\mathbf{A})$ viable cells $(n=22)$, $(\triangle)$ dead cells $(n=20)$.

MHz. In the case of rice cells, 19 cells out of 20 stained cells showed negative force while 18 cells out of 20 nonstained cells showed positive force as listed in Table 1(A). Therefore there was a clear correlation between the dielectrophoretic property and the PI staining property. The same correlation was obtained with BY-2 cells (Table 1(B)).

\section{Conclusion}

The application of a CFM to the dielectrophoretic cell selection was successful in the case of rice and BY-2 protoplasts. The CFM can be prepared easily and its shape is so slim that the CFM is useful for subsequent singlecell experiments on the microscope stage. Especially high throughput microinjection with high success rate is expected.
Table 1 Correlation between the dielectrophoretic movement at $15 \mathrm{MHz}$ and the PI staining property. Positive: movement towards CFM, Negative: movement apart from CFM, N. M.: no movement, $(+)$ stained with PI, (-) not stained with PI. (A) Rice single-cells, (+) $n=20,(-) n=20$. (B) BY-2 single-cells, $(+) \mathrm{n}=12,(-) \mathrm{n}=20$.

(A)

\begin{tabular}{ccccc}
\hline & & \multicolumn{3}{c}{ Dielectrophoresis } \\
& & Positive & N.M. & Negative \\
\hline \multirow{2}{*}{ PI staining } & $(+)$ & 0 & 1 & 19 \\
\cline { 2 - 5 } & $(-)$ & 18 & 2 & 0 \\
\hline
\end{tabular}

(B)

\begin{tabular}{ccccc}
\hline & & \multicolumn{3}{c}{ Dielectrophoresis } \\
& Positive & N.M. & Negative \\
\hline \multirow{2}{*}{ PI staining } & $(+)$ & 1 & 2 & 9 \\
\cline { 2 - 5 } & $(-)$ & 20 & 0 & 0 \\
\hline
\end{tabular}

\section{Acknowledgment}

This work was supported by a Grant-in-aid for Scientific Research, Scientific Research of Priority Areas: Single-Cell Molecular Technology, the Ministry of Education, Culture, Sports, Science, and Technology.

\section{References}

1) T. Matsue, N. Matsumoto, S. Koike, and I. Uchida, Biochim. Biophys. Acta, 1157, 353 (1993).

2) S. Ogata, T, Yasukawa, and T. Matsue, Bioelectrochemistry, 54, 33 (2001).

3) M. Saito, T. Chikazawa, H. Matsuoka, Y. Nishizawa, and N. Shibuya, J. Biotechnol., 76, 227 (2000).

4) M. Saito, Y. Kosai, and H. Matsuoka, Electrochemistry, 68, 333 (2000).

5) H. Matsuoka, H. Sotoyama, M. Saito, K.-B. Oh, and S. Horikiri, Bioelectrochem. Bioenerg., 49, 65 (1999).

6) H. Matsuoka, Y. Kosai, M. Saito, N. Takeyama, and H. Suto, J. Biotechnol., 94, 299 (2002).

7) H. A. Pohl, Dielectrophoresis, Cambridge University Press, 1978.

8) X. B. Wang, Y. Huang, X. Wang, F. F. Becker, and P.R. Gascoyne, Biophys. J., 72, 1887 (1997).

9) H. Morgan, M. P. Hughes, and N. G. Green, Biophys. I., 77, 516 (1999).

10) C. C. Chu, C. C. Wang, C. S. Sun, C. Hsu, K. C. Yin, C. Y. Chu, and F. Y. Bi, Sci. Sinica, 16, 659 (1975).

11) J. Kyozuka, Y. Hayashi, and K. Shimamoto, Mol. Gen. Genet., 206, 408 (1987).

12) E. M. Linsmaier and F. Skoog, Physiol. Plant, 18, 100 (1965). 